\title{
BAPTISTA, Jorge; MAMEDE, Nuno. Dicionário Gramatical de Verbos do Português. Faro: Universidade do Algarve Editora, 2020. 1117 p.
}

Oto Araújo VALE 1

Há uma tradição consistente da lexicografia em língua portuguesa que diz respeito à descrição da construção verbal. Francisco Fernandes publicou seu Dicionário de Verbos e Regimes em 1940, com abonações precisas e com uma visão original da regência. Essa obra, que se tornou uma referência incontestável, chegou a ter, pelo menos, 45 edições.

Um outro marco foi a publicação em 1990 do Dicionário Gramatical de Verbos do Português Contemporâneo do Brasil, trabalho realizado por linguistas da UNESP (campus de Araraquara) sob a coordenação do Prof. Francisco da Silva Borba. Aquele dicionário introduziu a noção de valência verbal na lexicografia brasileira e tinha critérios mais rigorosos no que se refere à seleção dos verbos. Isso se devia à introdução da linguística de corpus como norte para os estudos lexicográficos, tendo o dicionário registrado apenas os verbos realmente utilizados no Português do Brasil. Naquele momento, acontecia a revolução da informática pessoal, que permitia aos pesquisadores terem acesso a computadores, o que possibilitou a construção de um dicionário que tinha por base apenas e tão somente os verbos que haviam ocorrido no corpus utilizado, que era representativo da produção escrita dos últimos 50 anos no Brasil.

Houve outras iniciativas lexicográficas que contribuíram para o estudo dos verbos, sob perspectivas distintas, entre as quais cabe destacar o Dicionário Sintáctico de Verbos Portugueses, de 1994 coordenado pelo Prof. Winfried Busse, da Universidade de Berlin, ou ainda o Catálogo de Verbos do Português Brasileiro, da equipe dirigida pela Profa Márcia Cançado, da Universidade Federal de Minas Gerais, cuja primeira edição foi publicada em 2013.

Nesse sentido, o Dicionário Gramatical de Verbos do Português, de autoria dos professores Jorge Baptista, da Universidade do Algarve, e Nuno Mamede, do Instituto Superior Técnico da Universidade de Lisboa, ao mesmo tempo que dá continuidade a essa tradição, apresenta uma ruptura estabelecendo um novo padrão para esse tipo de dicionário, pelas próprias características do trabalho.

1 Universidade Federal de São Carlos (UFSCar), São Carlos, São Paulo, Brasil; otovale@ufscar.br; https://orcid.org/0000-0002-0091-8079 
De fato, temos aqui um dicionário cuja lista de verbos foi estabelecida a partir da frequência em corpus do português europeu. Foram selecionados os 4.000 verbos mais frequentes a partir de um corpus consolidado, o CETEMPúblico de Rocha e Santos (2000), e foram estudadas as colocações de cada um desses verbos, perfazendo um total de 5.500 construções verbais diferentes.

Os verbos se distribuem em 70 classes formais - estabelecidas anteriormente em Baptista (2012), inspiradas na metodologia do Léxico-Gramática de Gross (1975), Boons, Guillet e Leclère (1976) e Guillet e Leclère (1992). Cada uma dessas classes corresponde a um tipo de construção, entendida pelos autores como um conjunto constituído pela estrutura sintática, pelas propriedades estruturais, propriedades distribucionais e propriedades transformacionais de cada verbo.

Por estrutura sintática, compreende-se a extensão máxima (com o sujeito e os complementos essenciais e as preposições implicadas nesses complementos). As propriedades estruturais dizem respeito à natureza do sujeito e dos complementos. As propriedades distribucionais abrangem as restrições que cada verbo impõe para seu sujeito e seus complementos. $\mathrm{E}$ as propriedades transformacionais dizem respeito ao tipo de transformação que pode ser aplicado às frases construídas com cada verbo.

No que se refere às classes, a leitora encontrará a descrição sucinta de cada uma das 70 classes, explicitando cada estrutura, seus elementos, acompanhadas de um exemplo simples e claro.

$\mathrm{Na}$ sequência, os autores apresentam detalhadamente os símbolos que são utilizados para a descrição de cada estrutura. Essa descrição é acompanhada também de pelo menos um exemplo que demonstra de modo simples e preciso o uso desse símbolo.

Em seguida são apresentados os doze tipos de transformação que são descritas para os verbos. As transformações são entendidas aqui como operações formais existentes entre pares de frases que compartilham o mesmo conteúdo informacional. Esse elemento é importante, pois para cada entrada no dicionário são fornecidas frases-exemplo para cada uma dessas transformações.

São apresentados também os 50 papéis semânticos que são utilizados na descrição dos verbos e, finalmente, os 70 traços semânticos que caracterizam os elementos que preenchem as posições argumentais de cada verbo.

Um ponto importante é que todos os exemplos utilizados no dicionário foram retirados de corpus ou então foram gerados automaticamente por computador e revisados um a um, de modo a garantir que demonstrem bem o uso de cada verbo com 
uma construção prototípica. Os autores assinalam os exemplos retirados de corpus para diferenciá-los daqueles construídos automaticamente. Chamo especial atenção para esse ponto, pois ele vai determinar toda a estruturação de cada entrada.

De fato, nas entradas pode-se encontrar o grande diferencial do dicionário, pela forma como se encontram estruturadas. Os verbos aparecem em ordem alfabética. Primeiramente, temos o verbo, sua classe e um ou dois exemplos tipo. Em seguida, figuram a estrutura, com a explicitação do papel semântico de cada um dos argumentos e, caso seja necessário, a lista dos traços semânticos aplicáveis a esses argumentos.

Constam também do verbete cada uma das transformações, devidamente exemplificada, com a explicitação da estrutura. Esse é um ponto importante, pois demonstra como a descrição realizada para esse dicionário é poderosa, no sentido de se poder listar de maneira exaustiva os empregos dos verbos.

Por fim, alguns dos verbetes informam também sobre a ocorrência daquele verbo em expressões fixas.

Para exemplificarmos aqui, tomemos o verbo BATER, que conhecidamente tem vários empregos. De fato, esse verbo tem uma entrada com as classes ${ }^{2} 08$ (O Pedro bateuse por uma causa), 40 (O Pedro bateu com o livro na mesa), 32CL (A ave batia as asas) , 32H (O Pedro bateu o João na corrida), 35LD (A bola bateu na trave) e duas entradas nas classes 32R (O Pedro bateu o record mundial e O Pedro bateu as natas) e 35R (O Pedro bateu no João), além de uma série de empregos em expressões fixas, como: O Carlos bateu a bota, O Rui bateu a asa, O Zé bateu em retirada, O Zé não bate bem da bola.

Com se trata de um dicionário gramatical, não são indicados nas entradas os significados dos verbos. Por se tratar de verbos muito frequentes, os autores entendem que esse significado é facilmente acessível por meio da farta gama de exemplos fornecidos. $\mathrm{O}$ leitor brasileiro talvez estranhe alguns desses exemplos ou a ausência de alguns outros empregos. De fato, cabe aqui entender que a utilização desse dicionário por linguistas brasileiros pode justamente ajudar num mapeamento de diferenças léxico-sintáticas entre a variante europeia e o português do Brasil.

Por fim, cabe relembrar que o conjunto de dados que dá origem ao dicionário está já integrado a um analisador sintático, a base STRING (MAMEDE et al., 2012), que foi o que possibilitou a geração desse dicionário.

\footnotetext{
2 Para uma definição das classes, pode-se consultar Baptista (2012) em: https://www.inesc-id.pt/pt/ indicadores/Ficheiros/11313.pdf
} 


\section{Referências}

BAPTISTA, J. Viper: uma base de dados de construções léxico-sintáticas de verbos do português europeu. In: Actas do XXVIII Encontro da APL.APL, Faro, Portugal (2012). Disponível em: https://www.inesc-id.pt/pt/indicadores/Ficheiros/11313.pdf. Acesso em: 9 nov. 2020.

BOONS, J. P.; GUILLET, A.; LECLÉRE, C. La structure des phrases simples en français: constructions intransitives. Genéve: Droz, 1976.

BORBA, F. S. (coord.). Dicionário gramatical de verbos do português contemporâneo do Brasil. São Paulo: Editora UNESP, 1991.

BUSSE, W. Dicionário Sintáctico de Verbos Portugueses. Lisboa: Almedina, 1994.

CANÇADO, M.; GODOY, L.; AMARAL, L. Catálogo de verbos do português brasileiro: classificação verbal segundo a decomposição de predicados. v. 1. Verbo de mudança. Belo Horizonte: Editora UFMG, 2013.

FERNANDES, F. Dicionário de verbos e regimes. 45. ed. Porto Alegre: Globo, 2005 [1940].

GROSS, M. Méthodes en syntaxe. Paris: Hermann, 1975.

GUILLET, A.; LECLÈRE, C. La structure des phrases simples en français: constructions transitives locatives. Genebra: Droz, 1992.

MAMEDE, N.; BAPTISTA, J.; DINIZ, C.; CABARRÃO, V. String - a hybrid statistical and rulebased natural language processing chain for portuguese. In: PROPOR 2012, Coimbra, Anais... Coimbra 2012. Disponível em: https://www.inesc-id.pt/publications/8578/pdf. Acesso em: 9 nov. 2020.

ROCHA, P.; SANTOS, D. CETEMPúblico: Um corpus de grandes dimensões de linguagem jornalística portuguesa. In: NUNES, M. G. V. (ed.). Actas do V Encontro para o processamento computacional da língua portuguesa escrita e falada ( $P R O P O R^{\prime} 2000$ ) Atibaia, 2000. p. 131-140. Disponível em: https://www.linguateca.pt/Diana/download/ RochaSantosPROPOR2000.pdf. Acesso em: 10 nov. 2020. 
COMO CITAR ESTA RESENHA: BAPTISTA, Jorge; MAMEDE, Nuno. Dicionário Gramatical de Verbos do Português. Faro: Universidade do Algarve Editora, 2020. 1117 p. Resenha feita por Oto Araújo Vale. Revista do GEL, v. 17, n. 3, p. 352-356, 2020. Disponível em: https://revistadogel.gel.org.br/

DOI: http://dx.doi.org/10.21165/gel.v17i3.3044

Submetido em: 10/11/2020 | Aceito em: 11/11/2020. 